\title{
METAS EDUCATIVAS 2021: \\ LA PREPARACIÓN CIUDADANA PARA LA SOSTENIBILIDAD COMO ELEMENTO CLAVE DE LA EDUCACIÓN QUE QUEREMOS PARA LA GENERACIÓN DE LOS BICENTENARIOS ${ }^{1}$
}

\author{
Educadores por la sostenibilidad
}

El pasado mayo de 2008, los ministros de Educación reunidos en El Salvador asumieron un importante compromiso que puede tener enormes repercusiones en Iberoamérica: acoger la propuesta "Metas Educativas 2021: la educación que queremos para la generación de los Bicentenarios" y avanzar en la elaboración de sus objetivos, metas y mecanismos de evaluación regional, así como iniciar un proceso de reflexión para dotarlo de un fondo estructural y solidario.

Se iniciaba entonces un ambicioso proyecto que convierte a la educación en herramienta fundamental para el desarrollo de la región. Durante el mes de septiembre, el proyecto dio un importante paso al haber quedado concretas y descritas esas metas en un elaborado documento que tras ser entregado al Secretario General Iberoamericano, Enrique Iglesias, por parte del Secretario General de la OEI, Álvaro Marchesi, en septiembre de 2008, ha sido ampliamente difundido por la red.

La OEI hizo público este valioso documento, presentándolo como primera versión para el debate, lo que constituye un planteamiento excelente y muy necesario. Hace dos semanas abría una nueva etapa de participación y discusión colectiva de la propuesta presentada, con el fin de lograr el máximo acuerdo social y político antes de su redacción y aprobación definitiva en septiembre de 2010.

Nuestra contribución al debate abierto se centra en el papel que unas Metas tan ambiciosas y necesarias deben conceder a la educación para la sostenibilidad. $Y$ en ese sentido queremos recordar que la OEI ha sido la principal portavoz hasta el momento, en el ámbito iberoamericano -a través de la web www.oei.es/decada- del Ilamamiento de Naciones Unidas para que la educación de todas las áreas y todos los niveles contribuya a formar una ciudadanía preparada para participar en la construcción de un futuro sostenible. Gracias a ello, centenares de instituciones educativas y miles de docentes hemos asumido los objetivos de la Educación para la sostenibilidad. Estamos seguros, pues, de que esta dimensión de la educación será debidamente recogida como uno de los grandes retos y objetivos fundamentales en la versión definitiva de "La educación que queremos para la generación de los Bicentenarios".

${ }^{1}$ Boletín No 33, 23 de febrero de 2009. Década por una Educación para la Sostenibilidad. http:// www.oei.es/decada/boletin033.htm 
Por ello, en esta etapa de enriquecimiento del documento presentado en la XVIII Conferencia Iberoamericana de Educación, queremos contribuir al debate abierto impulsando la petición de que se incorpore explícita y destacadamente la preparación ciudadana para la sostenibilidad a las Metas Educativas 2021. Invitamos, pues, a quienes se han adherido a los objetivos de la Década, a participar activamente tanto con el envío de reflexiones como interviniendo en los foros de debate que se pondrán en marcha el 1 de marzo próximo. Les invitamos, en definitiva, a una lectura reflexiva del documento para el debate y al envío de aportaciones, a través de la web http://www.oei.es/metas2021/reflexiones.htm, que impulsen tanto la incorporación de la educación para la sostenibilidad -una dimensión indispensable en el Proyecto- como otras posibles mejoras del documento que deberá marcar la agenda educativa de los próximos años en Iberoamérica. Estamos convencidos de que ello contribuirá a avanzar en la construcción de sociedades más justas, democráticas y sostenibles. 